\title{
Features of the development of the need for reading in primary schoolchildren (results of applied research)
}

\author{
Anna Smakhtina ${ }^{1, *}$, Vera Bederkhanova ${ }^{1}$, Mariya Dontsova $^{2}$ and Lada Chepeleva ${ }^{1}$ \\ ${ }^{1}$ Kuban state University, Russia \\ ${ }^{2}$ Federal Research Centre The Southern Scientific Centre of the Russian Academy of The Sciences \\ (SSC RAS), Russia
}

\begin{abstract}
The article presents an empirical study results of the development of the need for reading in primary schoolchildren. In the theoretical part, the definition of the need for reading is given as an internal spiritual need, which in terms of meaning is delimited with the concept of «reading need» associated with motivations for reading. The conclusions presented in the study are based on the results of an expert survey $(n=91)$ conducted in schools of the Krasnodar Territory among primary school teachers. With the help of empirical research, the level of development needs for reading in primary school students was studied, the content of reading needs was determined, that is, the system of incentives for reading. The types of reading needs were determined empirically by means of factor analysis, the results of which made it possible to identify and describe 4 latent types of reading needs. The article also presents a methodology for determining the degree of mismatch between a reading attitude and real behavior (initiative and diligence), which was measured using vector indices. As a result of empirical research, it was found that the level of development needs for reading in primary schoolchildren is below the average, while this level is significantly lower in boys than in girls. It was also found that girls have a low mismatch between attitude and real behavior, which indicates an approximate correspondence of the need for reading and independence in the process of reading as a behavioral act. In boys, indicators of the mismatch of attitudes and behavior indicate a tendency to rational choice of a book with a low level of emotional need to read it.
\end{abstract}

\section{Introduction}

The formation of an active reading activity, the need for reading among junior schoolchildren is a task of paramount importance in pedagogical science and is one of the significant goals of the National Program for the Support and Development of Reading. Reading activity as a type of information and cognitive activity occupies a special place in the structure of the formation of a personality, its intellect, worldview, obtaining and

\footnotetext{
*Corresponding author: Annlogoped@yandex.ru
} 
deepening knowledge and communicative competence, being an element of the general cultural, social life of a person. The downward trend in reading activity is becoming a problem for an entire generation and, above all, is characterized by the transformation of the reading process $[1,5]$. Many modern researchers pay attention to the decrease in motivation in education as a systemic problem of modern schools, including motivation to read in elementary school $[13,18]$, which indicates the presence of a global problem. All this poses questions of rethinking the use of approaches in stimulating reading activity, searching for new scientific opportunities to form the need for reading, stimulating reading motivation in order to achieve high results in reading skills, general literacy and reading culture $[2,11,15]$.

In the modern world, reading activity as a process is undergoing the same serious changes as other areas of life. The development of information technology has changed the form of reading: the paper book is gradually being replaced by an electronic one. However, for children, especially those of primary school age, the format of the book plays a significant role. In the process of reading, personal life experience is correlated with the content of the book and, of course, with its graphic design. Experiencing the heroes' experiences fill the child's inner world with certain attitudes, which, as a result, shape the personality.

Interest is an essential aspect of the motivational sphere of any activity. Some scholars believe that need and interest are interchangeable concepts. are similar in terms of the defined goal - getting satisfaction - and are aimed at a specific object. However, the selected concepts are not identical, because interest arises on the basis of a need and is a means of satisfying it. The need expresses the need, and interest shows the liking, predisposition to some kind of activity. «Modern researchers in the field of reading consider the formation of the reader's need as a kind of information need, which is the basic one in the group of the spiritual needs of the individual» [4, p. 130]. This definition carries an equal sign with the concept of «need for reading».

In our work, we consider it necessary to distinguish between the concepts of «need for reading" and "reading need». The reader's need, from our point of view, should be associated with the idea of the motives for reading, that is, with what exactly prompts a person to read, the needs of the reader. The need for reading is, first of all, the awareness of the value of reading as a way of knowing the world, the awareness of the value of the information present in the book, the need to experience the social experience conveyed by the book. The need for reading is a spiritual need [4]. The reading need is the subjective reason why a person reads. The need for reading can be a reading need if reading as a process is a spiritual need. In the case of elementary school students, the need for reading, just as a spiritual need, is usually poorly formed and reading activity is more associated with the satisfaction of other needs, such as praise, aesthetic pleasure, self-presentation. The purpose of pedagogical influence is to form and develop precisely the need for reading as a spiritual need, which is an integral personal characteristic of the "reading person".

In this study, the goal is to assess the level of development needs for reading in primary schoolchildren, as well as to determine the structure of the teaching needs of the studied group. The driving force for realizing the reader's needs in real life is motivation. Motivation to read is understood as «individual's personal goals, values, and beliefs with regard to the topics, processes, and outcomes of reading» [10, p. 405]. The direct product of motivation is involvement (active participation in reading) [3], the development of which should become one of the goals of pedagogical influence.

Currently, the so-called theory of self-determination (SDT) is gaining momentum in modern pedagogical science, in which two types of motivation for reading are distinguished - autonomous and controlled types. Autonomous motivation is dictated by the internal attitudes of the personality and is the most productive type. The controlled type of 
motivation has two subspecies: external regulation (to read in order to receive a reward or to avoid punishment) and introjected regulation, when children take the initiative to read in order to show themselves in the best light in front of other people, usually adults [8]. Autonomous motivation is an intrinsic property of the individual and presupposes the presence of a feeling of pleasure and satisfaction from the reading process, a clear interest in reading [17]. Incomplete autonomous motivation manifests itself in the type of «identified regulation», which is also characterized by the presence of a sense of the importance, value of reading in the presence of external (controlled) motivation.

In the course of the research, the structure of motivation for the reading activity of younger students was studied. The work tested the hypothesis that the types of reading needs of primary schoolchildren can be determined based on the idea of the degree of rationality of motivation to read, in addition to existing theories, including the theory of self-determination (SDT). In the meaningful model, three types of motives were identified, which were classified according to the degree of rationality, based on the ideas described in the theory of social action by M. Weber [19]: goal-rational («to satisfy the desire of the parents, to get praise from the parents», «to get a good mark in reading, praise from the teacher»), value-rational («curiosity, desire to learn something new, something interesting for oneself», «to learn something that others do not know, to show oneself «cool» and «knowledgeable», self-presentation in front of others», «to learn more about the heroes of the cartoons you like (fairy tales, performances») and affective («the need for new sensations, the search for the strong emotional experiences», "self-identification with a literary hero, emotional connection with the heroes of the book, increasing self-esteem through the heroes», «see interesting pictures (get aesthetic pleasure»).

\section{Materials and methods}

The study presents the results of an expert survey conducted in February-March 2020. The experts were primary school teachers (grades 1-4) of secondary schools in the Krasnodar Territory (Krasnodar $(n=56)$, municipalities $(n=39))$. Statistical analysis of the data was carried out using the statistical package IBM SPSS Statistics 23.0. To study the distribution of the studied characters, the Kolmogrov-Smirnov test was used. Variables were considered normally distributed at $\mathrm{p}>0.05$. Statistical description of the features was performed using the arithmetic mean and standard deviation $(\mathrm{M} \pm \mathrm{SD})$. Comparison of the means of two independent samples was performed using the Student's t-test for normally distributed features and the Mann-Whitney U-test for features that do not obey the normal law. The structure of the reading needs of primary schoolchildren was studied using factor analysis. The selection of factors was carried out under the condition Total Initial Eigenvalues $>1$. Extraction Method: Principal Component Analysis. Rotation Method: Varimax with Kaiser Normalization.

\section{Results}

With the help of an expert survey, the degree of development needs for reading in children of primary school age was measured, which was assessed on a scale from 1 to 10 (1 - read because they must; 10 - read because they want to, on their own initiative). The results show that the general level of development needs for reading in primary schoolchildren can be assessed as «below average». The average expert assessment for this parameter is $3.69 \pm$ $2.44[\mathrm{M} \pm \mathrm{SD}]$. It was found that the development of the need for reading in girls is significantly higher than in boys $(p=0.002)$ (Table 1$)$. The obtained data on the presence of significant gender differences in the need for reading are consistent with the results of other 
studies [7-9, 16]. Moreover, L. Kavanagh claims that «Findings from large-scale assessments consistently show girls significantly outperforming boys on tests of reading achievement, and these gender differences transcend languages and cultures» [12, p.5]. This fact dictates the need to analyze the subject of research in the gender aspect.

Table 1. The expert assessments' results of the level of development needs for reading in primary schoolchildren $(\mathrm{N}=91)$.

\begin{tabular}{|c|c|c|c|}
\hline Scale & $\begin{array}{c}\text { Boys } \\
\boldsymbol{M} \pm \boldsymbol{S D}\end{array}$ & $\begin{array}{c}\text { Girls } \\
\boldsymbol{M} \pm \boldsymbol{S D}\end{array}$ & $\begin{array}{c}\text { Mann-Witney's } \\
\text { U-test. } \mathbf{p}\end{array}$ \\
\hline $\begin{array}{c}\text { The level of development needs } \\
\text { for reading }\end{array}$ & $3.14 \pm 2.17$ & $4.35 \pm 2.59$ & 0.002 \\
\hline
\end{tabular}

The methodology adopted in the study involves measuring the severity of the need for reading in children by gender, the degree of mismatch between attitudes (intensity of intention to read) and behavioral imperatives associated with the practice of reading. This method of measuring the need for reading is the author's adaptation of the method for calculating the indices of mismatch between the parameters of attitudes and real behavior, described in the works of A.V. Yadov [20] and V.S. Maguna [14].

Behavioral imperatives were understood as the development of independence in the choice of literature (children read what they choose) and diligence when it comes to the requirements of the curriculum or parents (cases when children read as needed). These indicators reflected, respectively, the scale of initiative and diligence (table 2.)

Table 2. Indicators and indicators used in the process of measuring the expert assessment of the development of the reading needs of primary school students.

\begin{tabular}{|c|c|c|c|}
\hline Code & Parameter & Indicator & Scale \\
\hline $\mathrm{A}$ & Attitude to reading & $\begin{array}{l}\text { Degree of the severity of the need } \\
\text { for reading (read because they } \\
\text { themselves want, on personal } \\
\text { initiative and motivation) }\end{array}$ & $\begin{array}{l}\text { Scale from } 0 \text { to } 10 \text {, } \\
\text { where } « 0 »-\text { read } \\
\text { only necessary, «10» } \\
- \text { read at will, } \\
\text { personal initiative }\end{array}$ \\
\hline I & $\begin{array}{l}\text { Initiative in reading } \\
\text { activity }\end{array}$ & $\begin{array}{l}\text { The degree of independence in the } \\
\text { choice of literature (they read what } \\
\text { they themselves choose according } \\
\text { to desire and personal interest) }\end{array}$ & $\begin{array}{l}\text { Scale from } 0 \text { to } 10 \text {, } \\
\text { where } « 0 »-\text { read } \\
\text { what they offer, } \\
« 10 » \quad-\quad \text { an } \\
\text { independent choice }\end{array}$ \\
\hline $\mathrm{D}$ & $\begin{array}{l}\text { Diligence in reading } \\
\text { activity }\end{array}$ & $\begin{array}{l}\text { The degree of diligence of children } \\
\text { when it comes to the requirements } \\
\text { of the curriculum or parents (cases } \\
\text { when children read as needed) }\end{array}$ & $\begin{array}{l}\text { Scale from } 0 \text { to } 10, \\
\text { where } \ll 0 » \text { is } \\
\text { absolutely not } \\
\text { executive, «10» - } \\
\text { very diligent }\end{array}$ \\
\hline
\end{tabular}

For these scales, gender averages were measured with the calculation of confidence intervals, which made it possible to compare the indicators for boys and girls. The degree of mismatch between attitudes and actions (MA) was measured using vector indices on the scales of initiative and dedication (formulas 1 and 2).

$$
\begin{aligned}
\mathrm{MA}_{|\mathrm{A}-\mathrm{I}|} & =\frac{\mathrm{A}-I}{\mathrm{~A}+I} \times 10 \\
\mathrm{MA}_{|\mathrm{A}-\mathrm{D}|} & =\frac{\mathrm{A}-D}{\mathrm{~A}+D} \times 10
\end{aligned}
$$

where MA ${ }_{|A-I, D|}$ - indicator of mismatch between attitude and initiative (or diligence) in reading practice, A - reading attitude (intensity of the intention to read), I - development of initiative in reading practice, D - development of diligence in reading practice. The measurement results for the presented scales and formulas are shown in Table 3. 
Table 3. Indicators of reading need and behavioral imperatives among primary school students.

\begin{tabular}{|l|c|c|c|c|c|}
\hline \multirow{2}{*}{ Scales } & \multicolumn{2}{c|}{ Boys } & \multicolumn{2}{c|}{ Girls } & $\begin{array}{c}\text { Gender } \\
\text { difference }\end{array}$ \\
\cline { 2 - 6 } & $\begin{array}{c}\text { Vector } \\
\text { index (MA } \\
\mid \text { A-I.D| }\end{array}$ & Mean & $\begin{array}{c}\text { Vector } \\
\text { index } \\
\text { (MA }\end{array}$ & Mean & $\begin{array}{c}\text { Euclidean } \\
\text { distance }\end{array}$ \\
\hline Initiative scale (I) & -1.20 & 4.00 & -0.36 & 4.67 & 17.09 \\
\hline Scale of performance (D) & -2.52 & 5.26 & -1.91 & 6.39 & 17.86 \\
\hline Attitude scale (A) & & 3.14 & & 4.35 & 19.82 \\
\hline
\end{tabular}

The indicator on the scale of initiative among boys and girls is lower than on the scale of commitment, which indicates the predominance of must in the attitudes of students, that is, younger students often read forcedly, on demand, than on their own initiative. The initiative scale indicates the action associated with self-selection of the book. In girls, the mismatch in this parameter with attitude is small ( -0.36 points), which indicates an approximate correspondence between the need for reading and independence in the process of reading as a behavioral act. In boys, the mismatch in this parameter is significantly greater $(-1.20)$, which indicates a rational choice of a book with a low level of emotional need to read it. The performance scale for both boys and girls has a rather high indicator, that is, children regularly read what they are asked by the school curriculum or their parents, but negative values of the indicator indicate that younger students do not really want to read, but do it according to necessary ( -2.52 and -1.91 , respectively).

Later, in order to formally prove the existence of the listed types of reading needs of primary school students, using factor analysis, 4 latent types were identified. It should be noted that most often in modern pedagogical research, the structure of reader motivation is explained precisely by the 4-factor model [6]. Our study, in this sense, somewhat differs in the content of the identified latent types in boys and girls. Thus, the strongest latent factor (Component 1, Total of Initial Eigenvalues $=1.57$ ) in boys includes two observed scales (Scale 1 and Scale 4), which have high factor loads $(0.772,0.801)$, and in girls - three (Scale 1, Scale 4, Scale 8) (Total of Initial Eigenvalues for Component 1=1.56) (table 4).

Table 4. Content of latent types of reading needs (results of factor analysis).

\begin{tabular}{|l|c|c|}
\hline \multicolumn{1}{|c|}{ Scales } & $\begin{array}{c}\text { Boys } \\
\text { No. of component } \\
\text { (Factor weight) }\end{array}$ & $\begin{array}{c}\text { Girls } \\
\text { No. of component } \\
\text { (Factor weight) }\end{array}$ \\
\hline $\begin{array}{l}\text { Scale 1. The need for new sensations, the search for } \\
\text { strong emotional experiences }\end{array}$ & Comp.1 (0.772) & Comp.1 (0.857) \\
\hline $\begin{array}{l}\text { Scale 2. Satisfy the wishes of the parents, receive } \\
\text { praise from the parents }\end{array}$ & Comp.2 (0.509) & Comp.2 (0.850) \\
\hline $\begin{array}{l}\text { Scale 3. Curiosity, desire to learn something new, } \\
\text { something interesting for oneself }\end{array}$ & Comp.3 (0.575) & Comp.3 (0.574) \\
\hline $\begin{array}{l}\text { Scale 4. Identification of oneself with a literary } \\
\text { hero, emotional connection with the heroes of the } \\
\text { book, increasing self-esteem through the heroes }\end{array}$ & Comp.1 (0.801) & Comp.1 (0.782) \\
\hline $\begin{array}{l}\text { Scale 5. Get a good reading grade, praise from the } \\
\text { teacher }\end{array}$ & Comp.4 (0.916) & Comp.3 (0.876) \\
\hline $\begin{array}{l}\text { Scale 6. See interesting pictures (get aesthetic } \\
\text { pleasure) }\end{array}$ & Comp.3 (0.759) & Comp.4 (0.858) \\
\hline $\begin{array}{l}\text { Scale 7. Learn something that others do not know, } \\
\text { show yourself «cool» and «knowledgeable», self- } \\
\text { presentation in front of others }\end{array}$ & Comp.2 (0.576) & Comp.2 (0.707) \\
\hline
\end{tabular}


Scale 8. Learn more about the characters of your

favorite cartoons (fairy tales, performances)

Comp.2 (0.776)

Comp.1 (0.714)

Let's call the first type of reader's need - «the need for new sensations and knowledge». The content of the second latent factor (Component 2) in both boys and girls is characterized by the desire for self-presentation, presenting oneself in a favorable light in front of parents and peers. Let's call this type the "need for self-presentation". The third and fourth types (Component 3 and Component 4) are different for boys and girls. In boys, the third type is more associated with obtaining aesthetic pleasure from communicating with a book (Scale 6, factor weight $=0.759)$, fueled by curiosity (Scale 3, factor weight $=0.575$ ). Let's call it «the need for aesthetic pleasure. «In girls, the third type (Component 3) strongly correlates with the rational need to get a good grade in school (Scale 5, factor weight $=0.876$ ), which is enhanced by curiosity (Scale 3 , factor weight $=0.574)$. Let's call this type - «rational need». The fourth latent factor (type of need) is unique (it is associated with only one scale). For boys, this is a connection with «rational need» (Scale 5, factor weight $=0.916$ ), which, unlike the case of girls, is not reinforced by curiosity, and for girls, with the need for aesthetic pleasure (Scale 6, factor weight $=0.858$ ), which is an absolutely independent phenomenon.

The severity of the identified latent types of reading needs in younger schoolchildren was measured by multiplying the relative frequency (share) of the experts' positive choice of the observed scales, which are components of this type, by the factor load. For example, in boys, type 1 «need for new sensations and knowledge» is described by parameters Scale 1 «Need for new sensations, search for strong emotional experiences» and Scale 4 «Identification of oneself with a literary hero, emotional connection with the heroes of the book, self-esteem increase through heroes». Factor loads for these scales are 0.772 and 0.801 , respectively. Then the severity (weight) of the latent type of reading needs is calculated as $0.772 * 0.319+0.801 * 0.363=0.536$ (table 5 ). The weighted scores of types in girls were calculated in a similar way (table 6).

Table 5. Formation logic' and measurements results of latent types for reading needs in boys.

\begin{tabular}{|l|l|l|l|l|l|}
\hline \multirow{2}{*}{ Type of reading needs } & Scales* $^{*}$ & Frecuency & $\begin{array}{l}\text { Proportion } \\
(\mathbf{p})\end{array}$ & $\begin{array}{l}\text { Factor } \\
\mathbf{w e i g h t} \\
(\mathbf{w})\end{array}$ & $\begin{array}{l}\text { Type } \\
\mathbf{w e i g h t} \\
\left(\mathbf{\Sigma} \mathbf{p}_{\mathbf{i}}^{*} \mathbf{w}_{\mathbf{i}} \mathbf{)}\right.\end{array}$ \\
\hline $\begin{array}{l}\text { Type 1 The need for new } \\
\text { sensations and knowledge }\end{array}$ & Scale 1 & 29 & 0.319 & 0.772 & \multirow{2}{*}{0.536} \\
\cline { 2 - 5 } & Scale 4 & 33 & 0.363 & 0.801 & \\
\hline \multirow{2}{*}{$\begin{array}{l}\text { Type 2 Need for self- } \\
\text { presentation }\end{array}$} & Scale 2 & 43 & 0.473 & 0.509 & \multirow{2}{*}{0.660} \\
\cline { 2 - 5 } & Scale 7 & 34 & 0.374 & 0.556 & \\
\cline { 2 - 5 } & Scale 8 & 24 & 0.264 & 0.576 & \multirow{2}{*}{0.618} \\
\hline $\begin{array}{l}\text { Type 3 Need for aesthetic } \\
\text { pleasure }\end{array}$ & Scale 3 & 45 & 0.495 & 0.575 & \multirow{2}{*}{0.473} \\
\cline { 2 - 5 } $\begin{array}{l}\text { Type 4 Need for aesthetic } \\
\text { pleasure }\end{array}$ & Scale 6 & 40 & 0.440 & 0.579 & \\
\hline
\end{tabular}

* the interpretation of the observed scales is disclosed in table 3 .

Table 6. Formation logic' and measurements results of latent types for reading needs in girls.

\begin{tabular}{|c|c|c|c|c|c|}
\hline Type of reading needs & Scales* & Frecuency & $\begin{array}{l}\text { Proportion } \\
\text { (p) }\end{array}$ & $\begin{array}{l}\text { Factor } \\
\text { weight } \\
\text { (w) }\end{array}$ & $\begin{array}{c}\text { Type } \\
\text { weight } \\
\left(\Sigma \mathbf{p}_{\mathrm{i}}^{*} \mathbf{w}_{\mathrm{i}}\right)\end{array}$ \\
\hline \multirow{3}{*}{$\begin{array}{l}\text { Type } 1 \text { The need for new } \\
\text { sensations and knowledge }\end{array}$} & Scale 1 & 29 & 0.319 & 0.857 & \multirow{3}{*}{0.775} \\
\hline & Scale 4 & 31 & 0.341 & 0.782 & \\
\hline & Scale 8 & 30 & 0.330 & 0.714 & \\
\hline \multirow{2}{*}{$\begin{array}{l}\text { Type } 2 \text { Need for self- } \\
\text { presentation }\end{array}$} & Scale 2 & 47 & 0.516 & 0.850 & \multirow{2}{*}{0.548} \\
\hline & Scale 7 & 14 & 0.154 & 0.707 & \\
\hline
\end{tabular}




\begin{tabular}{|c|c|c|c|c|c|}
\hline Type 3 Rational need & Scale 3 & 34 & 0.374 & 0.574 & \multirow{2}{*}{0.734} \\
\cline { 2 - 5 } & Scale 5 & 54 & 0.593 & 0.876 & 0.396 \\
\hline $\begin{array}{c}\text { Type 4 Need for aesthetic } \\
\text { pleasure }\end{array}$ & Scale 6 & 42 & 0.462 & 0.858 & 0.396 \\
\hline
\end{tabular}

* the interpretation of the observed scales is disclosed in table 3

The positive aspect of this approach is that the reading needs are complex and the described measurements reflect an objective picture of structural connections in the system of reading needs of younger students. Based on the results of calculating the frequency of choices by experts of incentives for reading (Table 5,6), it is impossible to single out any definite (dominant) motive. Although the experts most often named the rational goals «Get a good reading grade, praise from the teacher» (> 50\% of expert «votes») and «Satisfy the desire of parents, get praise from the parents» as an incentive to read younger students ( $>$ $47 \%$ ), factor analysis showed that these observed features do not have a direct relationship with one latent factor, but are either «unique» or are associated with other needs.

\section{Discussion}

The idea of measuring the development needs for reading based on the calculation of vector indices can become an impetus for the design of methods based on determining not the development level's of the need for reading as such, but the degree of initiative manifestation and diligence as empirical indicators of autonomy - external control in the system of motivation for reading of younger students. In this case, the development of the need for reading can become a latent sign. In work [9] it is noted that the upbringing of an autonomous type of motivation is possible through the use of teaching methods that support the innate psychological needs of students. The authors distinguish three types of essential needs that manifest themselves in the learning environment: the need for autonomy, the need for competence, and the need for belonging to significant others. The need for autonomy presupposes a high degree of initiative and responsibility. Supporting autonomy in the educational process involves presenting the possibility of choosing literature that will be of interest to students, recognizing these interests, respecting and considering students' points of view on the material read, encouraging the student's personal initiative [7]. The need for competence comes from the desire to achieve success, to get ahead of others, and the need to belong to significant others motivates the desire to please, to please, to experience praise and one's own significant in the eyes of others, which gives rise to a high degree of performance.

The ideas of the theory of self-determination (SDT), in frequency, characteristics of autonomous motivation for reading, including initiative and responsibility, have formed the idea that initiative is an indicator of autonomous motivation, and the degree of manifestation of the property of initiative can indicate complete, incomplete autonomy or lack of autonomy that comes to change of diligence (fig.1). This idea was implemented in the above expert survey (table 2).

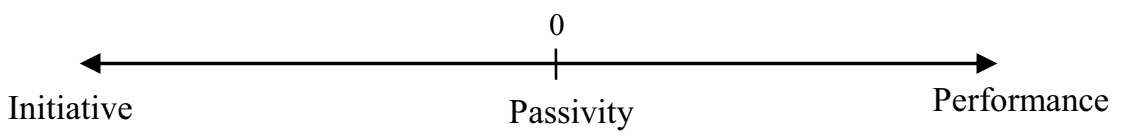

Fig. 1. Behavioral characteristics of motivation to read (complete autonomy - external control).

The results of the study of the structure of the reader's need among younger schoolchildren indicate the predominance of goal-oriented rational motives (praise, good marks). That is, the value for students is not the process of reading itself and the information in the book, but the result, expressed in external encouragement from adults. 
As a result, the predominance of the executive vector is absolutely understandable. However, these rational motives are not associated with each other, but are present in the reading activity of younger schoolchildren in conjunction with other motives that are more of a value and emotional nature. This fact was established by means of factor analysis, which made it possible to identify 4 latent types of reading needs among which the desire for self-presentation dominates in boys, and in girls, the desire to experience new emotional sensations, to gain new knowledge, as well as external stimuli, such as the desire to get good mark.

\section{Conclusions}

The results of the study showed that the development of the need for reading in primary school students is below the average and has gender differences. At first glance, the structure of reading needs is dominated by external (controlled) motivation, conditioned by rational motives (to get praise, a good mark), however, when identifying latent connections, it was determined that goal-rational motivation is only an addition to other (hidden) motives. For boys, this is the need for self-presentation (to show themselves, their knowledge, which will be appreciated). In girls, the rational component is closely correlated with the emotional one. Girls are curious, active, and interested in what they read. In view of the identified gender differences in the motivation of the reading activity of younger students, the pedagogical impact should also differ by gender. For the formation of the need for reading, it is necessary to find conditions, opportunities that could contribute to the development of reading activity - reading resources, the content of which must correspond to the technical and cultural development of society. The study of reading resources that have the greatest potential in shaping the need for reading is the topic of a separate study. However, based on the results of many studies, including ours, they should, first of all, foster initiative as the main indicator of the autonomy of reading activity.

\section{References}

1. P.A. Alexander, E.A. Fox, Theoretical models and processes of reading 5, 33-68 (2004)

2. A.J. Applegate, M.D. Applegate, The Reading Teacher 64(4), 226-234 (2010) doi:10.1598/rt.64.4.1

3. A.T. Barber, S.L. Klauda, Policy Insights from the Behavioral and Brain Sciences, 7(1), 27-34 (2020) doi: 10.1177/2372732219893385

4. L.N. Chernysheva, Values and meanings 3(19), 129-137 (2012)

5. V.P. Chudinova, Children's reading. The negative consequences of the development of media environment. Children and culture (Moscow, 2007)

6. M.H. Davis, S.M. Tonks, M. Hock, W. Wang, A. Rodriguez, Reading Psychology 39(2), 121-187 (2018) doi:10.1080/02702711.2017.1400482

7. J. De Naeghel, H. Van Keer, R. Vanderlinde, Frontline Learning Research 3, 83-102 (2014)

8. J. De Naeghel, H. Van Keer, M. Vansteenkiste, Y. Rosseel, Journal of Educational Psychology 104(4), 1006-1021 (2012) doi:10.1037/a0027800

9. F. De Smedt, A. Rogiers, S. Heirweg, E. Merchie, H. Van Keer, Frontiers in Psychology 11 (2020) doi:10.3389/fpsyg.2020.01678 
10. J.T. Guthrie, A. Wigfield, Engagement and motivation in reading. Handbook of reading research (Longman, New York, 2000)

11. J.L. Hedges, R. Gable, K-12 Education 31(1) (2016)

12. L. Kavanagh, Journal of Research in Reading, 1-21 (2019) doi:10.1111/14679817.12284

13. R.A. Lazowski, C.S. Hulleman, Review of Educational Research 86(2), 602-640 (2016) doi:10.3102/0034654315617832

14. V.S. Magun, Needs and psychology of social activity of the individual (Nauka, Leningrad, 1983)

15. B.A. Marinak, L.B. Gambrell, Literacy Research and Instruction 47(1), 9-26 (2008) doi:10.1080/19388070701749546

16. R. Mohd-Asraf, H. Abdullah, English Language Teaching 9(6), 134-140 (2016) doi: 10.5539/elt.v9n6p134

17. R.M. Ryan, E.L. Deci, American Psychologist 55, 68-78 (2000) doi:10.1037/0003066X.55.1.68

18. J. Smith, L. Smith, A. Gilmore, and M. Jameson, Learn. Individ. Differ. 22, 202-206 (2012) doi: 10.1016/j.lindif.2011.04.010

19. M. Weber, Economy and society: essays on understanding sociology (Higher school of Economics, Moscow, 2017)

20. V.A. Yadov, Methodological problems of social psychology (M., 1975) 